\title{
Results of a survey on human factors and perceptions during the first wave of the COVID pandemic
}

Manu L.N.G. Malbrain; Peter Rosseel, Valentina Della Torre, Heather Baid, Kaushik Bhowmick, Piotr Szawarski, Tapas Kumar Sahoo, Tuğhan Utku, Flavio Nacul, Adrian Wong

For the ESICM Working group on Human Factors

\section{Introduction and Aims}

- The current Corona virus pandemic poses an enormous pressure on healthcare systems around the world

- Human factors and non-technical skills do play a major role in dealing with such a crisis

- This survey was designed to

- check how physicians of all specialties and healthcare workers perceive the current pandemic and

- how they managed patients admitted to intensive care

\section{Methods}

- An online survey (accessible via: https://www.surveymonkey.com/r/COVID GENERAL)

- The survey consisted of 15 multiple choice or open questions.

- Personal additions and comments were possible after each question
- $N=221$

- Interim analysis

$-\mathrm{N}=203$

- 56 countries

- Most of the respondents resided in Europe

\section{Results - respondents}

$$
\begin{array}{lll}
- \text { Majority anaesthesia } & \text { Majority also } & \text { - Majority }>10 \text { years } \\
-\mathrm{N}=104 & \text { intensivist }(\mathrm{n}=169) & \text { experience }
\end{array}
$$

Results - Net Promotor Score
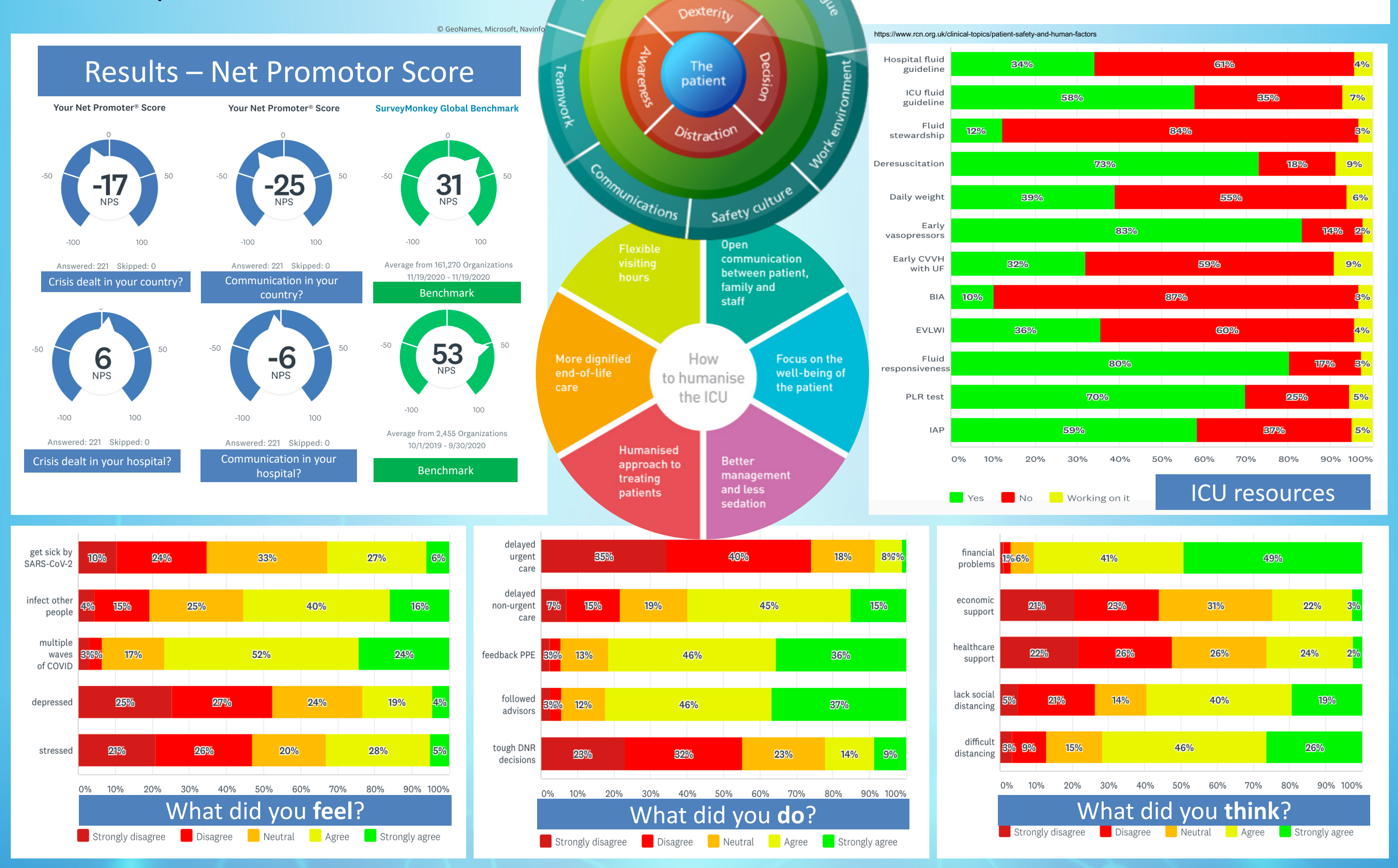
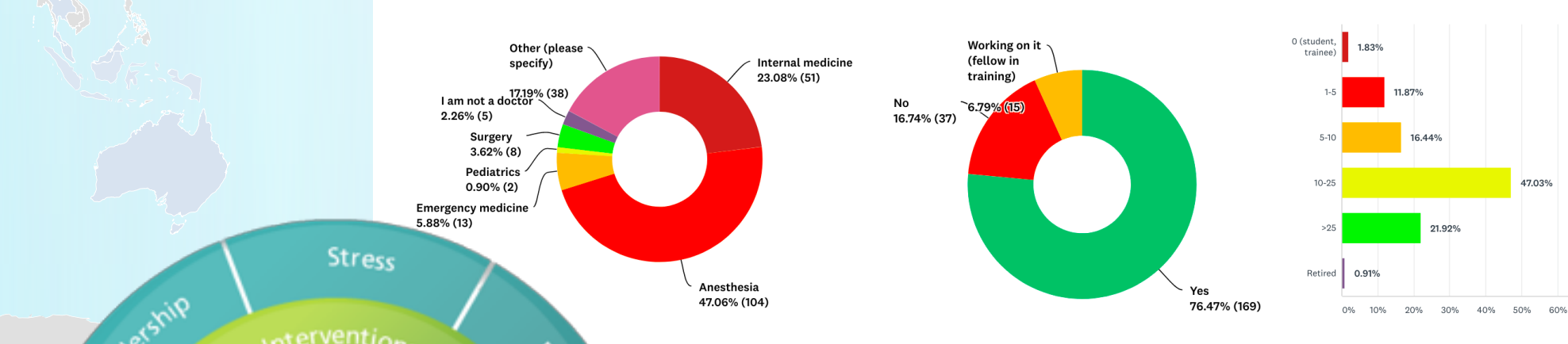

\section{Conclusions}

- This survey evaluated how physicians dealing with COVID-19 patients feel, think and act and how they used (ICU) resources

- The overall results show that there is still much uncertainty and a general feeling of disappointment on how the first wave was dealt with at all levels: society, hospitals, economic, healthcare but also on an individual level probably related to a lack of disruptive leadership

- Nontechnical skills and human factors seem to play an important role in dealing with a global pandemic 